\title{
Biology and Damage Pattern of Hairy Caterpillar Selepa celtis Moore (Lepidoptera: Nolidae) on Terminelia arjuna
}

\author{
Hanamant Gadad*, A. H. Naqvi, Vishal Mittal, Jitendra Singh and Susmita Das
}

Central Tasar Research and Training Institute, Central Silk Board, Ministry of Textiles: Govt. of India, PO-Piska-Nagri, Ranchi-835 303, India

*Corresponding author

\section{A B S T R A C T}

Keywords

Selepa celtis,

Fecundity, Egg,

Larval, Pupal

periods and larval

instars

Article Info

Accepted:

04 December 2020

Available Online:

10 January 2021
The life history of Selepa celtis Moore was studied during Aug-Sept- 2019 under laboratory conditions at Central Tasar Research and Training Institute, Ranchi, Jharkhand. Gravid female was observed laying eggs with the fecundity of $150.60 \pm 39.32$ eggs. Incubation period of eggs was 3-4 days. Total larval, pre pupal and pupal period were observed to be 16-22, 1-2 and 8- 12 days, respectively. Adult longevity was ranged from 2-6 days. During the study nature of damage was also observed in the field and it has been found that this pest is gregarious and causes the damage by defoliating the foliage. In early instars larvae feeds by scraping the chlorophyll content of the leaves and later instars known to cause skeletonization of the leaves by feeding the whole leaf except mid rib and veins of the leaves.

\section{Introduction}

Selepa celtis is regularly occurring nocturnal, polyphagous, multivoltine lepidopterous pest. The larvae of $S$. celtis are polyphagous in nature, sometimes causing epidemic defoliation. of various forest tree species viz. Albizia spp, Bischofia javanica, Careya arborea, Duabanga grandiflora, Elaeodendron glaucum, Ficus glomerata, Gme Jina arborea, Lagerst roemia spiciosa, Lannea coromafldelica. Mangifera indica, Schleichera trijuga, Shorea rohusta, Syzygium cuminii, Terminalia bellerica, $T$. catappa, T. chebula, T. myriocarpa, $T$. tomentosa Xylia dalbriformia, Acacia nilotica and Embllca officinalis in different parts of the country (Beeson, 1941; Browne, 1968; Khan et al., 1985; Joshi and Meshram 1989, Rizvi 2010, Haldhar et al., 2019 and Tripathy et al., 2020). This pest is distributed throughout Peninsular India, Madhya Pradesh, Tamil Nadu, and West Bengal Nagaland (Sharma, 2014; Shubhalaxmi et al., 2011).

Diagnostic characters of this pest are eggs are laid in masses and freshly laid eggs will be yellowish and translucent with round shape with reticulate markings on chorion. The 
larvae of this defoliator are highly active, hairy, and yellowish with black dots on abdominal tergites. In adults vertex, frons and thorax are pale brown; forewings are long and narrow, pale brown with a purplish-grey tinge, traces of sub basal and medial waved black lines, a double post medial line excurved round end of cell and enclosing a blackish circular path; hind wings are small and broad, whitish, suffused with fuscous towards outer margin (Sharma, 2014). Bharpoda et al., 2009 studied seasonal occurrence of $S$. celtis and reported that this pest is known to be active between the months of May-January. Where as Khatua 1997 reported that peak incidence of S. celtis is during the month of April in Sal forest. Damaging symptoms includes larvae cause damage by defoliating the leaves. Early instar larvae causes damage by feeding the epidermal layer of the leaves by scraping. However late instars larvae causes the defoliation/skeletisation of the leaves. This pest is known to complete 6-8 generations annually as reported by Jianfen and Zenghe, 1990; Si-ming, 2007.

In the recent years incidence of this pest is frequent on Terminelia arjuna which is a important host plant of tasar silkworm. However there is no record on biology of this pest on T. arjuna. With this background in present study on biology and nature of damage of $S$. celtis on important tasar silkworm host plant ( $T$. arjuna) has been carried out.

\section{Materials and Methods}

Larvae of Selepa celtis collected from Terminelia arjuna plantation of Central Tasar Research and Training Institute, Ranchi and which has served as nucleus culture. Further it has been reared under laboratory condition to obtain the egg masses to study the biology.
After getting the egg masses from nucleus culture one eggs mass was placed into petri plates (9 $\mathrm{cm}$ diameter). Eggs were monitored daily till hatching. After hatching freshly hatched larvae $(n=30)$ were separately reared under petri plates in 5 batches. Fresh tender leaves were provided for newly hatched larvae and observed daily till and adult emergence. Each batch of insects were observed daily for their development and survival. Observations on incubation, larval period, pre pupal erod, pupal period, fecundity and adult longevity were recorded.

\section{Incubation period}

Egg incubation period was recorded as the duration of time taken from egg laying to hatching, which was recognized by hatching of the larva through the egg chorion.

\section{Larval period}

The duration of larval period was recorded as the number of days taken from hatching of egg to the pupation of last instar larva. To determine the number of larval instars observation on number of molts (based on the molted skin of previous instar larva) were made on to know the different instars duration. The process was continued till pupal stage.

\section{Pupal period}

Pupal period was recorded by considering the number of days took from pupation to adult emergence. Total development period from egg to adult was computed by counting the data obtained from observations and the data regarding the duration of various stages of the pest were presented.

\section{Adult longevity}

The life span of adults was recorded by enclosing twenty male and twenty female 
adults in separate cages with 10 per cent honey solution.

\section{Fecundity}

Fecundity was recorded for five females (pre mated) by counting the number of eggs laid during the oviposition period for each female.

\section{Nature of damage}

Visual observations were made under the field to know the nature of damage and documented through photography.

\section{Results and Discussion}

The biology $S$. celtis was studied under laboratory conditions on $T$. arjuna at mean temperature $\left(27 \pm 2^{\circ} \mathrm{C}\right)$ and relative humidity $(75 \pm 5 \%)$. The results are presented in Table 1 . The life cycle of $S$. celtis consists of five developmental stages viz., egg, larva, prepupa. pupa and adult stage (Fig. 1). Eggs are laid in groups on the upper and lower surfaces of the leaves. A brief description of each development stage is illustrated hereunder.

\section{Incubation period}

Eggs were small, oval or oblong, microscopic, creamy white in colour when laid and later turned to yellow and finally to black before hatching (Fig. 1). Incubation period ranged from 3 to 4 days with a mean of $3.25 \pm 0.71$ days (Table 1). The present results are comparable with the findings of Shah (1996) who reported the egg period of $S$. celtis as $4.08 \pm 0.73$. Marginal difference might be due to the difference the host plants used in the studies.

\section{Larva}

During the present study, larva undergone four moults and five larval instars were observed. Based on exuviae in each moulting the instars were recognised.

\section{First instar larva}

First instar larva was cream or light yellow colour with prominent black head. Larvae was having fine hairs which are laterally arranged and length of hairs arising from terminal segments were comparatively longer (Fig. 2). They were very sensitive and immediately after hatching started feeding the epidermis and chlorophyll content of the leaves by scraping. The duration of first instar larva was 3-5 days with a mean of $3.60+0.71$ days (Table 1).

\section{Second instar larva}

Second instar larva was light yellow color with black head and laterally arranged hairs (Fig. 2). The duration of second instar larva ranged from 2 to 5 days with a mean of $2.95 \pm 0.82$ days (Table 1). They are comparatively bigger in size and they also feed on the chlorophyll content of the leaves by scraping the leaf epidermis (Fig. 2).

\section{Third instar larva}

Third instar larva were mustard yellow in colour with dark brown head and also exhibits 3 black spots on $1^{\text {st }}, 6^{\text {th }}$ and $8^{\text {th }}$ abdominal tergites and these were observed on fourth and fifth instars also (Fig. 2). At this instar the larvae were more active, fed more and size increased gradually than the first and second instars. Third instar larvae feeds by skeletonising the leaves. The duration of third instar larva ranged from 3 to 5 days with a mean of $4.15 \pm 0.67$ days (Table 1 ).

\section{Fourth instar larva}

Fourth instar larva was orange in colour with dark brown head. Body segmentation was 
more prominent and Hairs were oriented laterally at each segment (Fig. 2). Fourth instar larvae were voracious feeders. The duration of fourth instar larva ranged from 4 to 6 days with a mean of $4.35 \pm 0.74$ days (Table 1).

\section{Fifth instar larva}

Fifth instar larva was almost similar to the fourth instar larvae without any major morphological difference. However size of the larvae was bigger than the fourth instar larvae and larval skin was very thin and transparent to see the thin lining of the alimentary canal in the form of short median greenish strop on the dorsal side (Fig. 2). Larval duration of fifth instar was 3.20 \pm 1.05 and it was ranged between 2-4 days (Table 1). The total larval period of $S$. celtis ranged from 16 to 22 days with a mean of $18.25 \pm 2.12$ (Table 1). These results are close in agreement with the findings of Shah (1996) who reported that, the larval period of $S$. celtis was $17.33 \pm 0.99$.

Table.1 Biology of Selepa celtis reared on Terminelia arjuna

\begin{tabular}{|c|c|c|}
\hline Developmental stages & Development period (Days) & Range \\
\hline Incubation & $3.25 \pm 0.71$ & $3-4$ \\
\hline I $^{\text {st }}$ Instar & $3.60 \pm 0.75$ & $3-5$ \\
\hline II $^{\text {nd }}$ instar & $2.95 \pm 0.82$ & $2-5$ \\
\hline III $^{\text {rd }}$ Instar & $4.15 \pm 0.67$ & $3-5$ \\
\hline IV $^{\text {th }}$ instar & $4.35 \pm 0.74$ & $4-6$ \\
\hline $\mathrm{V}^{\text {th }}$ Instar & $3.20 \pm 1.05$ & $2-4$ \\
\hline Total larval period & $18.25 \pm 2.12$ & $16-22$ \\
\hline Pre Pupal period & $1.30 \pm 0.47$ & $1-2$ \\
\hline Pupal period & $9.85 \pm 1.22$ & $8-12$ \\
\hline Adult Longevity & $4.10 \pm 1.11$ & $2-6$ \\
\hline Male & $3.00 \pm 0.79$ & $2-4$ \\
\hline Female & $5.25 \pm 0.71$ & $4-6$ \\
\hline Total life cycle (Egg-Adult) & $33.5 \pm 2.52$ & $29-36$ \\
\hline Fecundity & $150.60 \pm 39.32$ & $110-200$ \\
\hline
\end{tabular}

Fig.1 Life cycle of Selepa celtis depicting different developmental stages

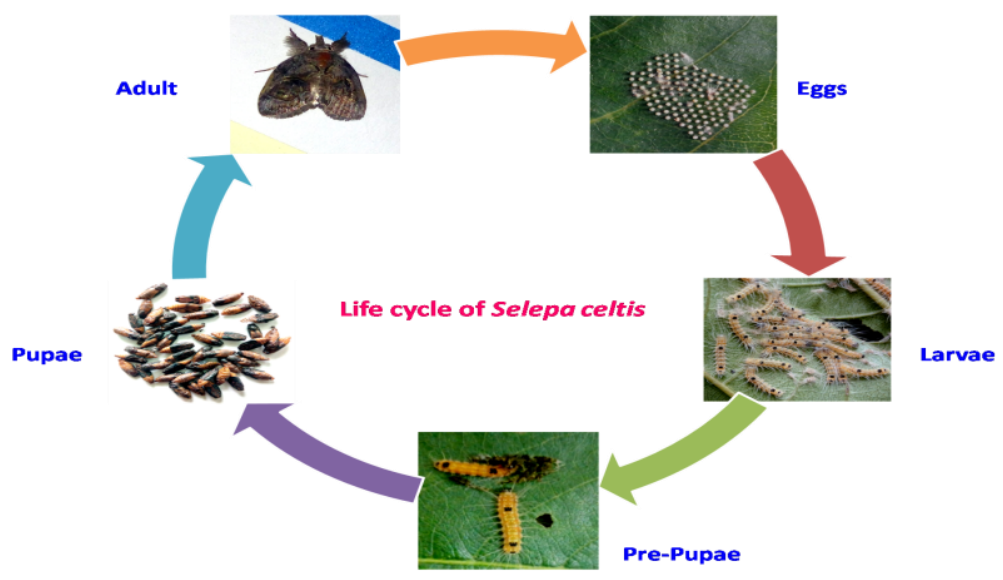


Fig.2 Larval instars of Selepa celtis a) First instar b) Second instar c) Third instar d) fourth instar e) Fifth instar
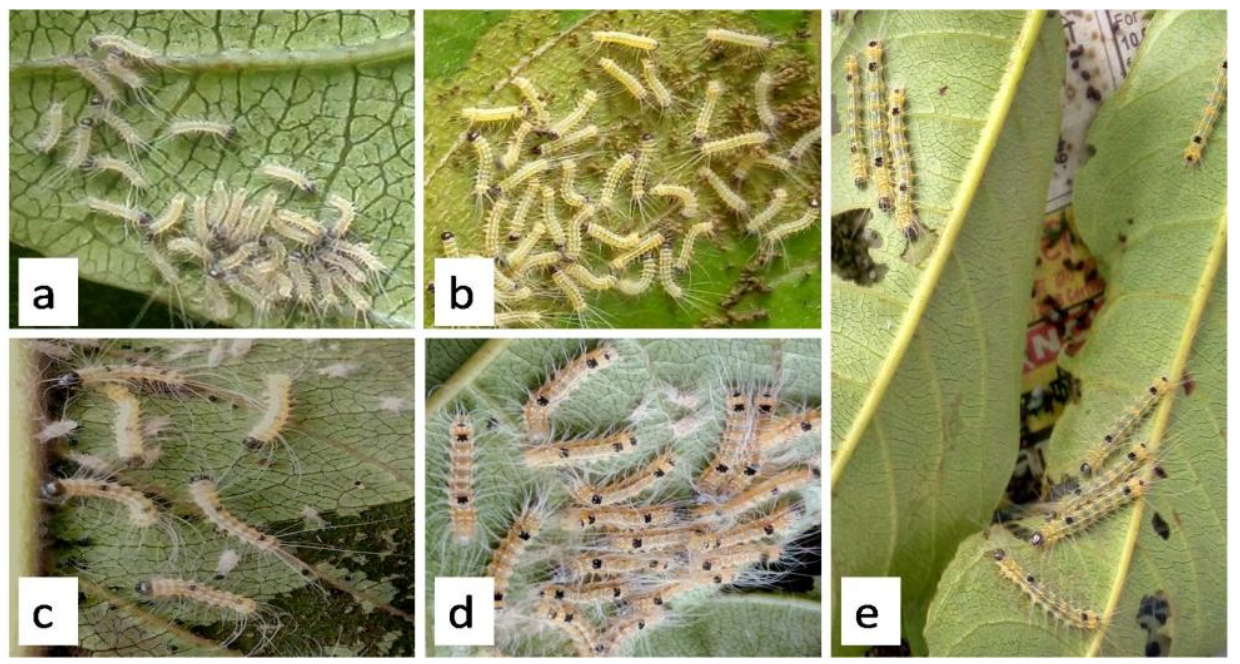

Fig.3 Damage caused by Selepa celtis A) Damage due to early instar larvae ( $1^{\text {st }}$ and $2^{\text {nd }}$ instars); B) Damage due to late instar larvae $\left(3^{\text {rd }}, 4^{\text {th }}\right.$ and $5^{\text {th }}$ instars $)$

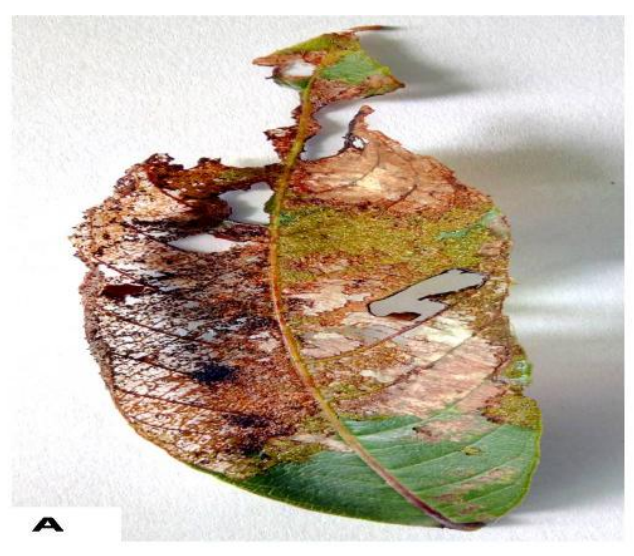

\section{Pre pupa and pupa}

During pre pupal stage late instar larvae $\left(5^{\text {th }}\right.$ instar) stops feeding and larval body length gets shrunken. Mature larvae did not pupate immediately it was quiescent for $1.30 \pm 0.47$ days with the range of 1-2 days (Table 1). During this period larvae construct protective silken case and pupate inside it. Pupa is small in size with dark brown colour and flattened ventrally (Fig. 1). Recorded mean pupal duration was $9.85 \pm 1.22$ days and it ranged between 8 to 12 days during the study (Table 1).

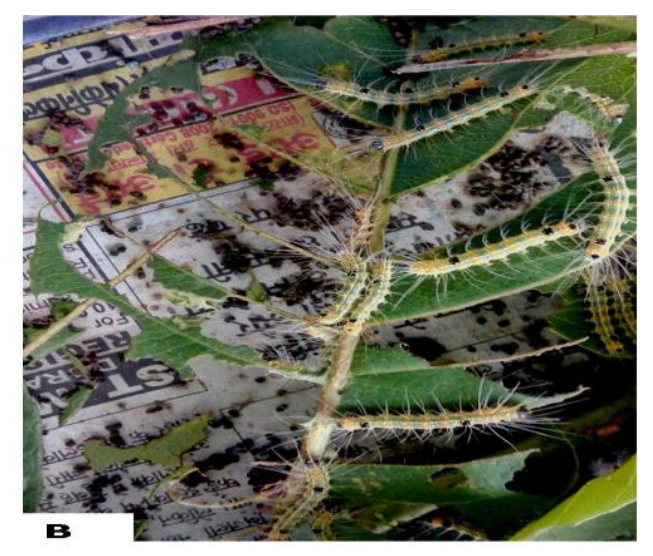

Adult moth: adults are medium in size with head and thorax are dark brown in colour (Fig. 1). Abdomen is slender with tapering end in males and blunt in females. Adult longevity was ranged 2 to 6 days with the mean of $4.10 \pm 1.11$ days. Between males and females males were short lived for 2-4 days where as females lived for days 4-6 days (Table 1).

Damage pattern: field observations on nature of damage revealed that $S$. celtis is a gregarious defoliating pest. In early instars 
larvae feeds by scraping the chlorophyll content of the leaves and later instars are voracious feeders and known to cause the skeletonising the leaves by feeding the whole leaf except mid rib and veins of the leaves (Fig. 3).

Results obtained during the present study are in agreement with the findings of Shah (1996) with certain marginal difference in the biological parameters. This variation might be due to the difference in the host plant used during both the studies. Results cannot be discussed further since the literature related to the $S$. celtis is very scanty and this is the first systematic report of this pest on Terminelia arjuna.

\section{Acknowledgments}

Authors expressing sincere gratitude to Dr. P. R. Shashank, Scientist, Indian Agricultural Research Institute, New Delhi for help rendered in the morphological identification of the hairy caterpillar Selepa celtis.

\section{References}

Beeson, C. F. C. (1941). The ecology and control of forest pests of India and the neighbouring countries. Vasnth Press. Dehradun Pp. 767

Bharpoda, T. M., Koshiya, D. J. and Korat. D. M. (2009). Seasonal occurrence of insect-pests on aonla (Emblica officinalis Geartn) and their natural enemies Karnataka Journal of Agricultural. Science., 22(2): 314-318.

Browne, F. G. (1968). Pets and diseases of forest plantation trees. Clarendon Press, Oxford. 1330 pp.

Gaurav Sharma. (2014). Studies on Odonata and Lepidoptera fauna of foothills of Aravalli Range, Rajasthan. Rec. zool. Surv. India, Occ. Paper No., 353: 1104.
Haldhar, S. M., Chet Ram, and Singh, D. (2019). Biotic stress (insect) of aonla (Emblica officinalis) in arid region of India: a review. Journal of Agriculture and Ecology, 7:16-6.

Joshi, K. C. and Meshram, P. B. (1989). A new report of Selepa celtis Moore (Lepidoptera: Noctuidae) as a pest of Babul (Acacia nilotica) and Aonla (Emblica officinalis). Indian Forester, 115(11): 847.

Khan, H. R, Prasas L and Kumar. S., (1985). Some important forest pests of Madhya Pradesh and their control. Presented in forestry conference, M.P., SFRI, Jabalpur. 18-10 February.

Khatua, A. K. (1997) occurrence and seasonal fluctuation of some lepidopterous defoliators of Sal (Shorea robusta) in Godapiasal, Midanapore, West Bengal. Indian Forester, 123 (1), pp. 37-44.

Rizvi, A. N. (2010). Nematodes associated with Insect Pests and Soil of Teak and Sal Forests of Dehradun (Uttarakhand), India. Records of the Zoological Survey of India, Dec. Paper No., 317: 1-141. (Published by the Director, Zoological Survey of India, Kolkata)

Shah, R. H. (1996). Bionomics and control of aonla hairy caterpillar, Selepa celtis Moore. M.Sc thesis: Gujarat Agriculture University. Anand. pp. 1198.

Shubhalaxmi. V., Roger. C., Kendrick, Vaidya. A, Kalagi. N and Bhagwat A. (2011). Inventory of moth fauna (Lepidoptera: Heterocera) of the Northern Western Ghats, Maharashtra, India. Journal of the Bombay Natural History Society, 108(3) 183-205.

Si-ming, C. A. I. (2007). Bionomics and control of Selepa celtis Moore. Forest Research; 2007-05

Tripathy, M. K., Parida, G and Behera, M. C. 
(2020). Diversity of insect pests and their natural enemies infesting Sal (Shorea robusta Garten f.) in Odisha. Journal of Entomology and Zoology Studies; 8(3): 1812-1822.
Wu Jianfen and Huang Zenghe. (1990). A preliminary report on the control of Selepa celtis Moore with several insecticides; Forest Research; 05

\section{How to cite this article:}

Hanamant Gadad, A. H. Naqvi, Vishal Mittal, Jitendra Singh and Susmita Das. 2021. Biology and Damage Pattern of Hairy Caterpillar Selepa celtis Moore (Lepidoptera: Nolidae) on Terminelia arjuna. Int.J.Curr.Microbiol.App.Sci. 10(01): 25-31.

doi: https://doi.org/10.20546/ijcmas.2021.1001.004 